\title{
COVID-19 and the Challenges of Transition to Online Learning
}

\author{
Barbara Grah \\ University of Ljubljana, Faculty of Economics, Slovenia \\ Sandra Penger \\ University of Ljubljana, Faculty of Economics, Slovenia
}

\begin{abstract}
The COVID-19 pandemic has changed the world. It changed the way we do business, and it changed our lives in terms of socializing. Nevertheless, it also brought essential changes in the educational segment. This school year, at the tertiary level, courses' contents and examinations are primarily done online in Slovenia due to the pandemic. In this paper, we examine the perceptions and challenges the third-year students of the Learning and knowledge management course conducted at the School of Economics and Business, University of Ljubljana, are facing. Specifically, we are interested in the challenges the students encountered during the transition to online learning due to the COVID-19 pandemic and the advantages and disadvantages of online learning, as perceived by students. What was used as the method to collect and analyze the data was personal reflection and content analysis. The findings show that students are facing different challenges. Nevertheless, also several advantages and disadvantages related to the online learning process are identified. We conclude by providing practical examples for pedagogical staff to ease the transition for students and avenues for future research.
\end{abstract}

Keywords: COVID-19, online learning, emergency online teaching, challenges, advantages, disadvantages

JEL classification: 121

Acknowledgments: The authors acknowledge that the Slovenian Research Agency partly financially supported the paper, Program P5-0364 - The Impact of Corporate Governance, Organizational Learning, and Knowledge Management on Modern Organization. We also wish to thank students for attending the Learning and Knowledge Management course for participating in our study.

Paper type: Research article

Received: Apr 25, 2021

Accepted: Oct 11, 2021

DOI: 10.54820/CFNS6611 


\section{Introduction}

The COVID-19 pandemic changed our lives. If possible, a vast part of people works from home. Also, the educational sector had to close its doors and transition to the online educational process. It brought essential consequences for the students involved, ranging from negative, such as experiencing technical challenges, social isolation, health problems, to positive ones in terms of no need for commuting and therefore essential cost savings. The objective of this paper is to study the challenges the third-year students of the Learning and knowledge management course conducted at the School of Economics and Business, the University of Ljubljana, encountered, during the transition to online learning due to the COVID-19 pandemic, as well as the advantages and disadvantages of online learning, as perceived by students. The research questions are: RQ1: How did the COVID -19 pandemic influence students? RQ2: What are the advantages of transition to online study due to the COVID-19 pandemic, as students perceive?; RQ3: What are the disadvantages of transition to online study as a consequence of the COVID-19 pandemic, as perceived by students? To understand the phenomena under study, we collected the data by surveying with open-ended questions and performed the content analysis next to NVivo analysis related to the fundamental changes students identified due to COVID-19 pandemics and the advantages and disadvantages of the transition to online courses.

\section{Literature review}

\section{COVID-19}

The outbreak of COVID-19, a respiratory disease, started in the Hubei Province of the People's Republic of China, and within a few months, it quickly spread worldwide. COVID-19 belongs to coronaviruses, which Tyrell and Bynoe first described in 1966. The symptoms of COVID-19 are similar to those of other respiratory diseases, such as fever, nasal congestion, fatigue, cough, next to the other upper respiratory tract infections, and usually start within a week. The danger of the COVID-19 is that it can progress to severe diseases, such as dyspnoea or pneumonia, and in some cases, to death. Meanwhile, some infected people have no evident symptoms and might even not know they have COVID-19 disease and might transmit it unconsciously to other people. First studies showed that older people are at the highest risk; however, younger ones can face severe consequences. The danger of the COVID-19 outbreak is its possibility of high reproduction, which can paralyze health systems (Velavan et al., 2020), as, for example, happened in Italy in 2020.

The latest threat to global health does not affect only healthcare systems worldwide but goes far beyond. To be able to save lives of as many as possible patients with severe symptoms, which is only doable when the health system is not paralyzed, as a mitigation strategy, countries across the globe took specific measures which were unimaginable by the majority of the world population just a few years ago. There are numerous temporary restrictions to travel, social distancing, isolations and quarantines, and, nevertheless, school and inevitable business closures on behalf of telecommuting (Fauci et al., 2020). Several vaccines against COVID-19 were developed. However, it is still not clear how long a specific vaccine will be effective.

Concretely, at the beginning of the pandemic, the Government of the Republic of Slovenia took several measures to prevent the spread of the pandemic, for example, closing schools, kindergartens, and bars, next to stopping public transport, a temporary ban on the gathering of people, limited traffic on the borders, a 
temporary ban on direct selling goods and services to consumers with some exceptions. The measures were taken also required suspension of the provision of preventive health services, except for those whose omission could have negative consequences for the patient's health, prohibited operation of restaurants, hotels, wellness services, gambling services, and fitness as well as other recreational services, cinemas, museums and galleries, hairdressers, beauticians. The courts held hearings and decided only in urgent cases. The administrative units limited the implementation of tasks to the minimum necessary, which stopped public life (Government of the Republic of Slovenia, 2020). Later measures demanded people to wear face masks in public areas, and a curfew during nighttime was enforced. According to the COVID-19 ongoing situation, those measures were later eliminated to a fuller or lesser degree, and if needed, accepted again, depending on the continuing COVID-19 situation, but not stopped until today, e.g., limit on the gathering of people, wearing face masks, particular protocols for border crossing, etc.

According to COVID-19 Sledilnik (2021), an official Slovenian site for monitoring the statistics related to the COVID-19 pandemic in Slovenia, the $1^{\text {st }}$ confirmed case in Slovenia was announced March 4, 2020. By May 11, 2021, there had been 247,449 confirmed cases in Slovenia. Out of that number, 17,424 patients were admitted to the hospital, and in total, 234,189 patients recovered, and 4.302 patients died. By May 11, 2021, in total, 496,204 people were vaccinated with one dose and 256,083 with two doses of vaccinations approved in the EU (by AstraZeneca, BioNTech, and Pfizer, Moderna, and Janssen Pharmaceutica NV) (European Commission, 2021). According to the World Health Organization (World Health Organization, 2021), there have been 159,319,384 cumulative total reported cases and 3,311,780 cumulative total deaths worldwide, as of 6:00 pm CEST, May 12, 2021. Americas had 63,960,023 cases and 1,562,442 deaths, Europe 53,134,851 cases and 1,111,412 deaths, SouthEast Asia 26,660,141 cases and 322,390 deaths, Eastern Mediterranean 9,538,922 cases and 191,342 deaths, Africa 3,372,715 cases and 84,295 deaths, meanwhile Western Pacific region experienced 2,651,986 cases and 39,886 deaths. Due to all the measures taken, the education sector moved the pedagogical process online in numerous countries worldwide, including Slovenia.

\section{Online learning}

Globalization and the fast development of information-communication technologies (ICT) caused several fundamental changes in teaching and learning. Since then, some universities and schools have transformed, and some new was formed to focus on online learning to take advantage of ICT and improve the cost-effectiveness and quality of the learning experience for their students (Abrioux, 2008). However, the online courses need to be adequately designed to attract students, challenge them to connect new knowledge to the existing one, and stimulate them to acquire new knowledge and their metacognitive thinking (Ally, 2008).

Ally (2008, p. 4) defines online learning as "the use of the Internet to access learning materials; to interact with the content, instructor, and other learnings, and to obtain support during the learning process, to acquire knowledge, to construct personal meaning, and to grow from the learning experience." different similar terms exist, which are sometimes interchangeably used for online learning, such as elearning, distributed learning, tele-learning, virtual learning, computer-assisted learning, and distance learning. Regarding the abovementioned terms, the common assumption is that the student and the pedagogue are not at the same place and at the same time. There is a distance among them, and the students use 
some technology to interact with the pedagogue and among each other's, meanwhile, the pedagogue provides support.

It is important to note that there are different expectations and perceptions of the learning environment regarding distance learning, e-learning, and online learning. However, the use of terminology is inconsistent. In their study, the identified differences might be in a hierarchy, e.g., distance learning as the broadest, elearning as a subtype of distance learning, and online learning as a sub-level of elearning; media type; access type; correspondence; and interaction. Distant learning can be understood as providing access to learning to geographically distant students; e-learning still has some uncertainty of the term. However, it is based on the premise that all forms of it (applications, programs, objects, and websites) can provide a learning opportunity for a student. Also, online learning is vaguely defined, although it most commonly stands for the access to learning experience via technology, e.g., as the newer, improved version of distance learning (Moore et al., 2011 ). Online learning can be synchronous (live lectures and real-time interactions, instant feedback, social interaction) or asynchronous (different learning systems and forums).

Tanis (2020) studied the seven principles of online learning. The most crucial principle (to Faculty and alumni) is holding students to high-performance standards, academic honesty, and professional conduct. The study showed that alumni positioned engagement with their Faculty higher than meeting with other students and course content. Tanis (2020) further claims students need a well-organized and communicative pedagogue in the online classroom. For universities, the classrooms must be solidly designed to involve students who are timely in their work.

Several advantages of online learning exist, for example (Dhawan, 2020; Ally, 2008; Bączek, 2021):

- accessibility - no location limitations, continuous access to material

- affordability (lower commuting and accommodation cost),

- flexibility (time-wise),

- comfortable surroundings,

- learning pedagogy.

On the other hand, the disadvantages of online learning are (Dhawan, 2020, Baczek, 2021):

- problems related to technology (login, audio, and video, downloading errors, installation),

- students can find it boring or unengaging,

- lack of social interactions,

- personal attention,

- mediocre course content,

- difficulties in understanding instructions.

The move to an online environment was essential during the COVID-19 pandemic for schools and universities, banned from conducting classes on their premises. Some schools, universities were better, while others were not so well prepared for the changed circumstances. At this point, we would also like to draw attention to the new term used to denote online learning as a response to the COVID-19 pandemic, namely emergency remote teaching (teaching in a hurry with bare minimum resources to provide temporary access to instructions), to separate it from the online learning (regular, adequate online instructions) (Hodges et al., 2020).

There have been some studies related to online learning due to the COVID-19 pandemic, for example, the one of Adnan et al. (2020), who found that online learning cannot produce desired results in underdeveloped countries like Pakistan 
because the majority of students cannot access the internet due to monetary and technical issues. In addition, the study of Mukhtar et al. (2020) found that the advantages of online learning during the COVID-19 pandemic are to be found in remote learning, accessibility, and comfort. Meanwhile, the key disadvantages are inefficiency and difficulty in maintaining academic integrity. The study of Fauzi et al. (2020), focusing on elementary schools, found that teachers are well aware of the context of online learning. However, the disadvantages are to be found in its implementation, namely the 1) available facilities, 2) network and internet usage, 3) planning, implementation, and evaluation of learning, and 4) parents collaboration.

\section{Methodology}

The study aimed to examine the perceptions and challenges of the third-year business students enrolled in the Learning and Knowledge management course (in the Slovene language) related to the online delivery of courses' contents and examinations due to the COVID-19 pandemic. To collect the content-rich data for gaining a deeper understanding of the research phenomenon, the surveys with open-ended questions were conducted among the students enrolled at the course Learning and Knowledge management, conducted at the School of Economics and Business, the University of Ljubljana in the school year 2020/2021. Out of 26 students, 14 responded with valid answers. To analyze the qualitative data, we first implemented content analysis. It is a systematic and replicable technique for compressing text into a few content categories with specific rules (Stemler, 2000) to offer the readers data presented quantitatively, in addition to the inclusion of the context-rich proof quotations students' reflections on COVID-19 related changes. We also performed NVivo analysis related to the fundamental changes students identified due to COVID-19 pandemics and the advantages and disadvantages of transitioning to online courses. To do that, we translated students' reflections into English and analyzed each question separately to find out which are the 50 most often used words (with synonyms).

In our study, 14 students, concretely four male $(28,6 \%)$ and $10(71,4 \%)$ female, participated in the survey with valid answers. Their average age was 22.4 years. All respondents were full-time students enrolled in the Learning and Knowledge Management class, a particular course for third-year bachelor degree students. The majority of them $(92,9 \%)$ had prior working experiences.

\section{Results}

\section{COVID-19 influence on students}

Regarding the RQ1 how the COVID-19 pandemic influenced students, they named several different perspectives: unfavorable, neutral, mixed, and favorable. Concretely, $64,3 \%$ complained about lack of socialization, $42,9 \%$ mentioned transition to online study, meanwhile lack of job opportunities for students and changed student life and habits (in terms of closed libraries, no meetings with schoolmates, which required adaption in study habits) was mentioned by $35,7 \%$ of respondents. The fifth most frequent change was the lack of freedom $(28,6 \%)$, followed by lack of sports and training, traveling, and additional stress $(21,4 \%)$. Students also mentioned closed bars (14,3\%), meanwhile time savings (no commuting, improved work-study balance, etc.), and more time spent with families, which improved family relations (both 14,3\%), were identified as positive consequences. One respondent $(7,1 \%)$ also experienced mental health challenges. Also, relaxation for a short time, in the beginning, new job opportunities and new 
experiences, more time for hobbies, and personal growth were identified on the positive side (all 7,1\%). One student also missed the entire operation of public transportation, as presented in Figure 1. Figure 2 illustrates the most often used words by students regarding how the COVID-19 pandemic influenced them. As shown, they emphasized most socializing, study, and their work/job opportunities. To offer the readers an in-depth understanding, we provide selected proof quotations in Table 1.

Figure 1

Changes related to COVID-19 as perceived by students

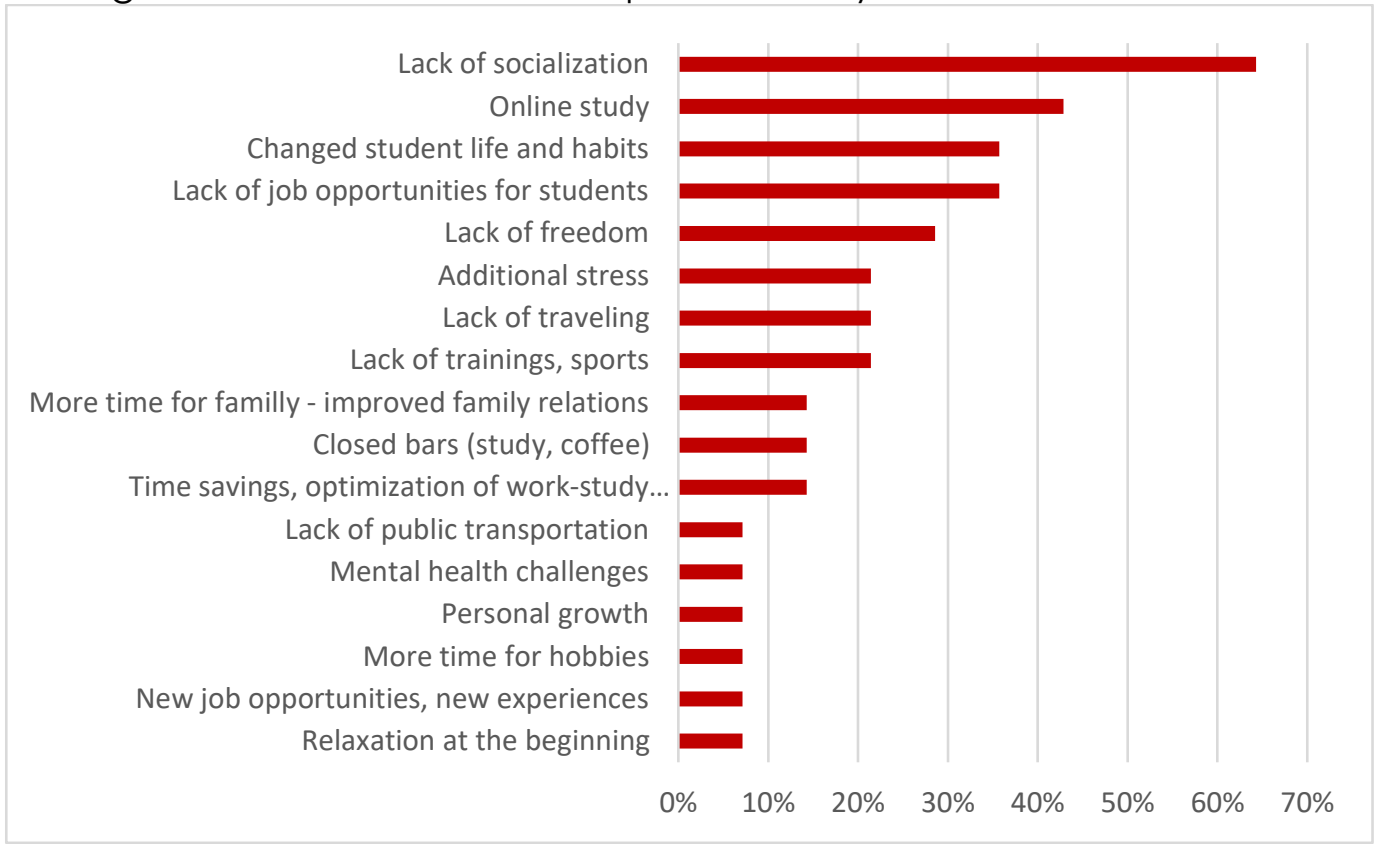

Source: Authors' work

Figure 2

Changes related to COVID-19 as perceived by students - Nvivo analysis

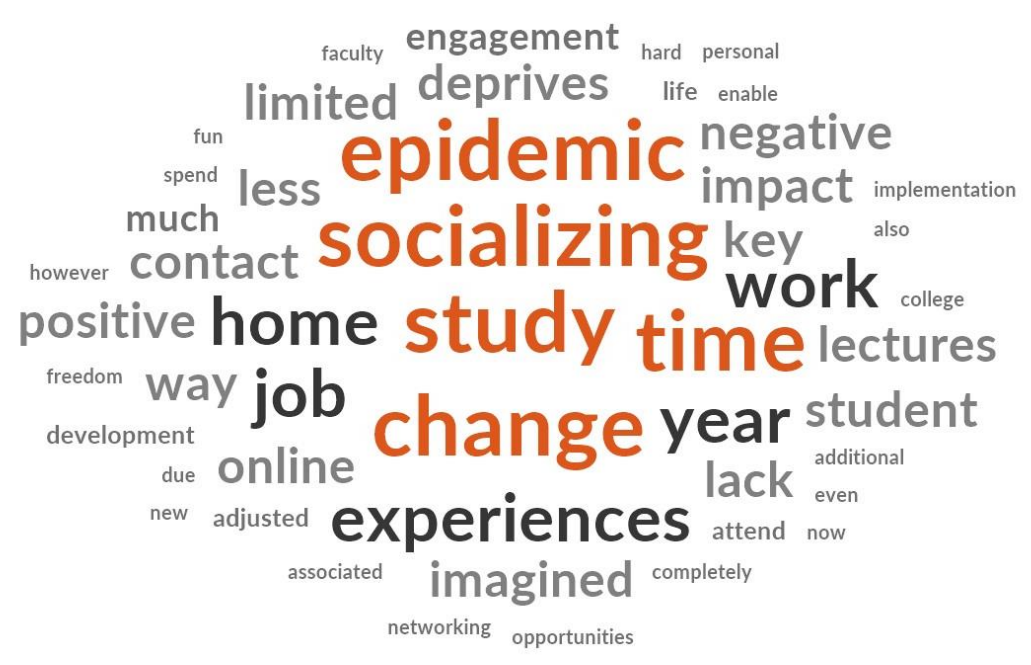

Source: Authors' work 
Table 1

Selected proof quotations

\begin{tabular}{|c|c|c|}
\hline Respondent & Proof quotation & Perspective \\
\hline R11 & $\begin{array}{l}\text { "The epidemic has a strong negative impact on me. Losing } \\
\text { contact with friends, the inability to travel and the absence } \\
\text { of nightlife this year completely changed my lifestyle, } \\
\text { thinking, and mental health stability. I think the real impact } \\
\text { will show in the consequences in a couple of years." }\end{array}$ & Negative \\
\hline R13 & $\begin{array}{l}\text { "Above all, it is about different adjustments and new } \\
\text { circumstances. However, I have adjusted, especially } \\
\text { regarding the online study." }\end{array}$ & Neutral \\
\hline R14 & $\begin{array}{l}\text { "The pandemic had a negative and positive impact on me. } \\
\text { As a key change, I would point out a smaller amount of } \\
\text { contacts (talking, socializing) with peers. However, more } \\
\text { time spent with my family and time savings due to the online } \\
\text { implementation of the pedagogical process." }\end{array}$ & Mixed \\
\hline R4 & $\begin{array}{l}\text { "The epidemic indirectly positively affects me, as far as the } \\
\text { combination of study and work are concerned. I have a } \\
\text { hard time imagining that I could work and, at the same } \\
\text { time, regularly attend lectures and tutorials at the faculty } \\
\text { premises. The key change for me was gaining the job } \\
\text { opportunity for further work and thus practical } \\
\text { engagement." }\end{array}$ & Positive \\
\hline
\end{tabular}

Source: Author's study

\section{Advantages of online study}

Regarding the RQ2, we asked the students about the advantages of online study. The majority mentioned time-related advantages, e.g., time savings and better time management $(78,6 \%)$. The second most important identified advantage was no need for commuting $(35,7 \%)$, followed by more options regarding the environment (e.g., more cozy, different options) as well as less anxiety and tremor when students need to participate (both $21,4 \%$ ) actively.

In addition, students also mentioned the advances of digital solutions (e.g., speed of results as well as joining online work without pedagogical staff, the possibility to multitask during the lectures as well as the increased flexibility (e.g., ability to join also when sick, etc.) (14,3\%). In addition, some other advances were recognized, such as a healthier lifestyle due to home cooking, improved online skills, and improved discussions (all $7,1 \%)$. One participant $(7,1 \%)$ identified no advantages, as presented in Figure 3. Figure 4 presents the NVivo analysis of the benefits students perceived. They emphasized work in terms of having more workload and other working experiences and better time management due to online study and no need for commuting. 
Figure 3

Identified advantages of online study

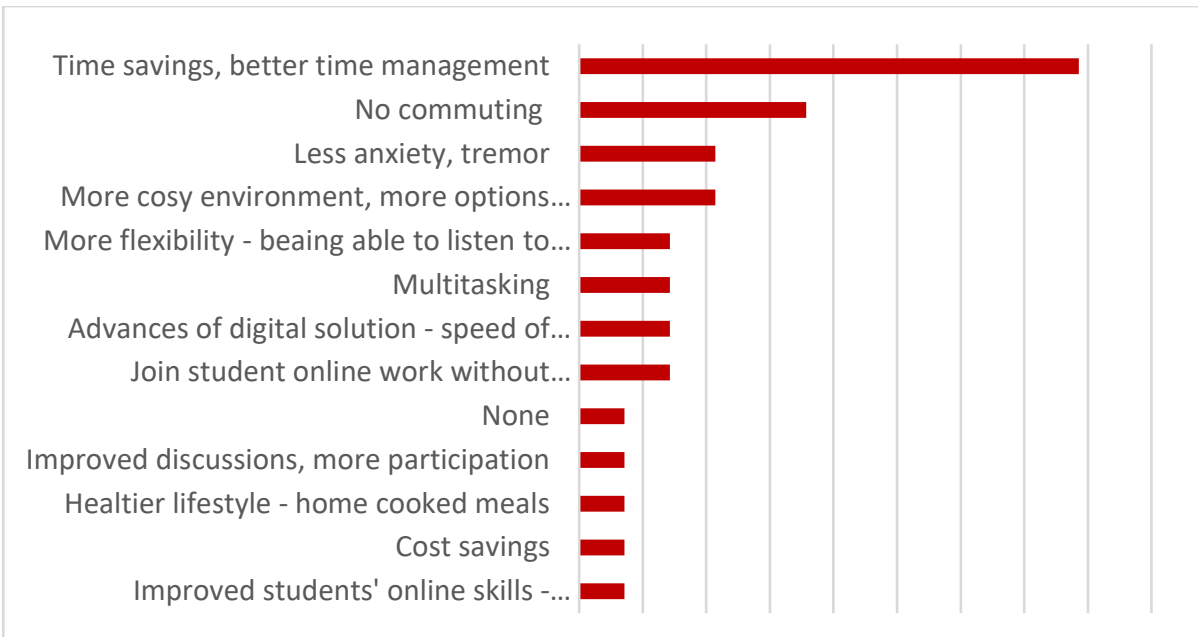

$0 \% 10 \%$ 20\% 30\% 40\% 50\% 60\% 70\% 80\% 90\%

Source: Authors' work

Figure 4

Identified advantages of online study - Nvivo analysis

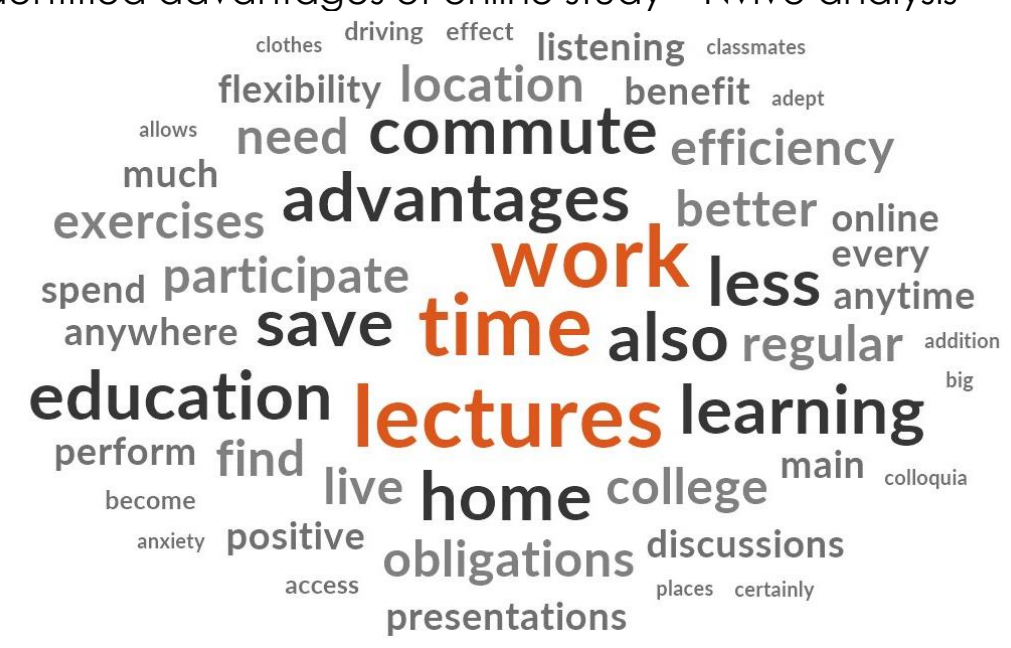

Source: Authors' work

Disadvantages of online study

Regarding RQ3, the most often identified disadvantage of online study is the lack of social contact with schoolmates $(57,1 \%)$. Students also feel they have more work to do during the semester, and they claim they have less motivation and focus, and they pinpointed technical problems (all 21,4\%). In addition, they identify the higher possibility of joining or leaving lectures in terms of more flexibility and multitasking, more disturbances during exams (e.g., noisiness), less authenticity, monotonous, and broken work-study-life balance (14,3\%). Participants also pinpointed stricter professors and more challenging exams, different exam guidelines for various courses, too strong focus on digital solutions without proper instructions, inconvenience they experience during cameras in terms of invasion in private space, and lack of non-verbal communication (see Figure 5). Figure 6 presents the 
NVivo analysis of identified disadvantages of online study. The primary issue pointed by students is a lack of in-person contacts.

Figure 5

Identified disadvantages of online study

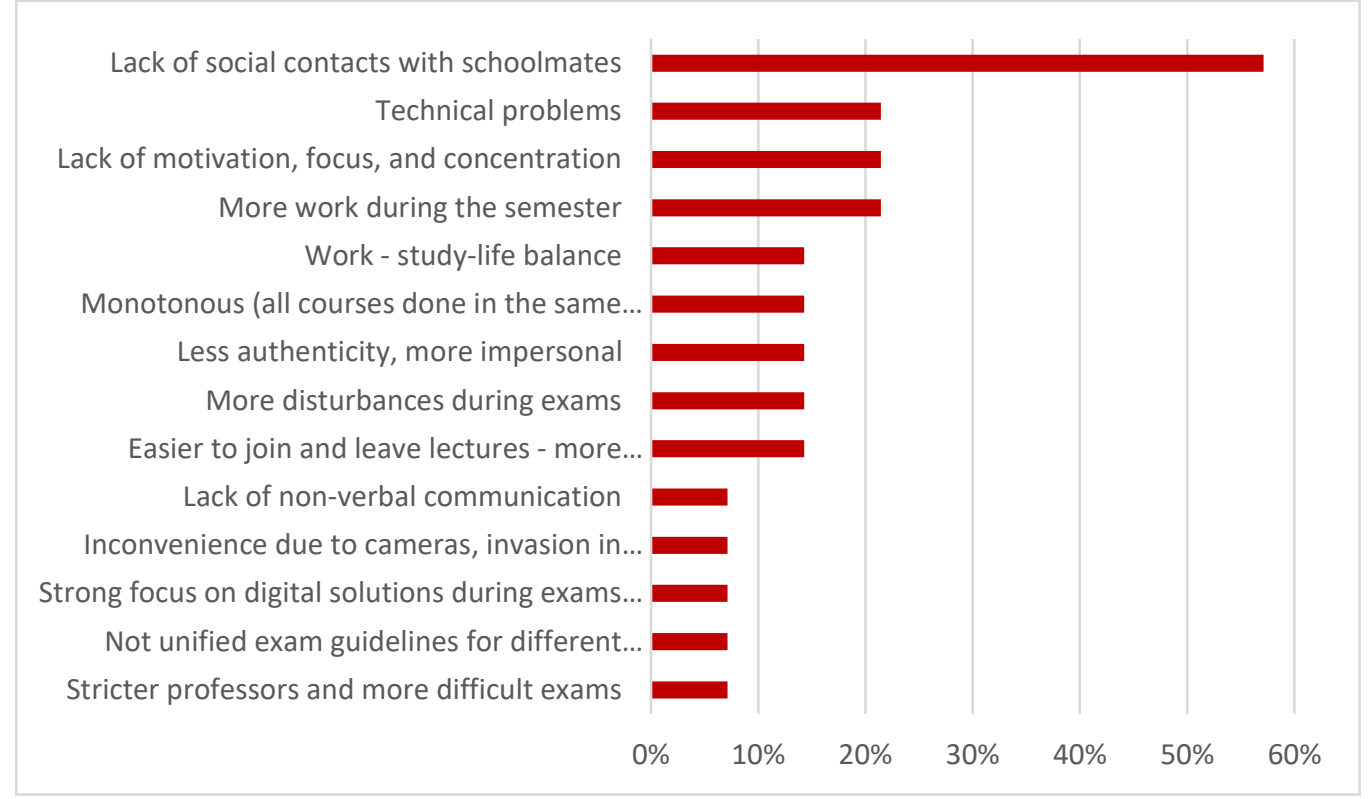

Source: Authors' work

Figure 6

Identified disadvantages of online study - Nvivo analysis

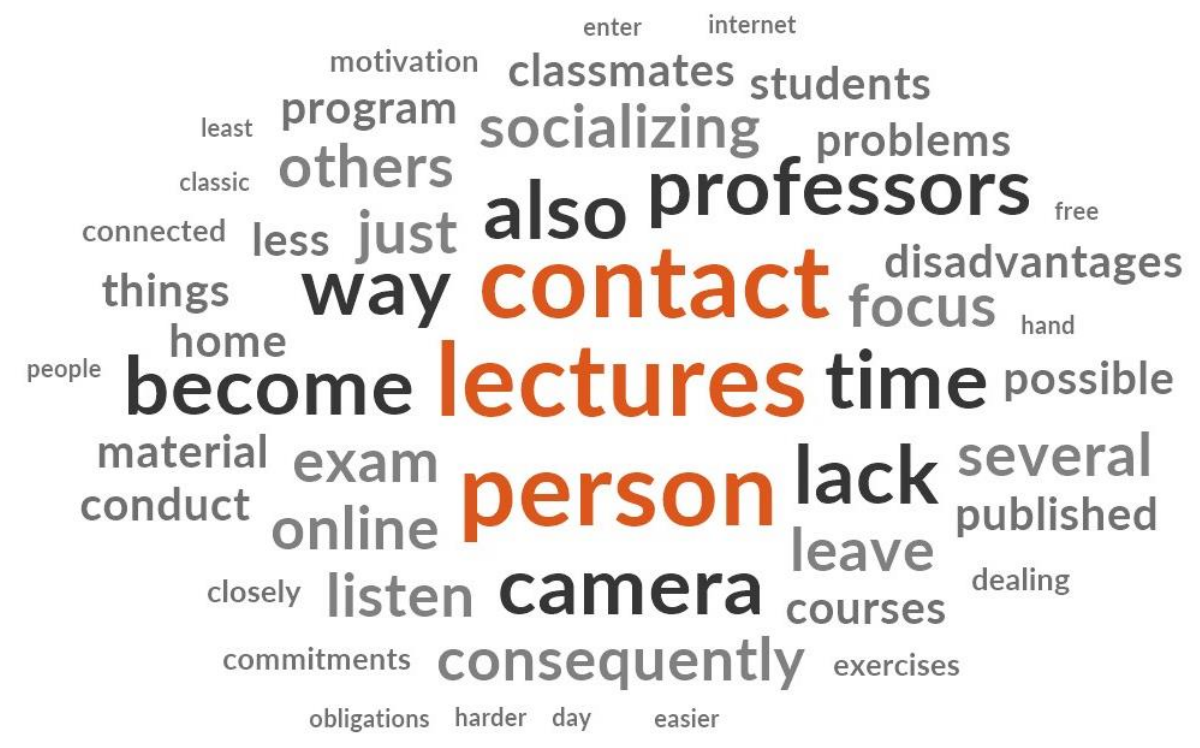

Source: Authors' work

Additional findings of research analysis

The additional question focused on their beliefs regarding the pedagogical process in the future. Out of 14 students, $35,7 \%$ believe it will be conducted in a hybrid form, $21,4 \%$ believe it will return to the classical way, and also $21,4 \%$ of students believe it will go entirely online. The combination of hybrid or completely online was identified 
in $14,3 \%$. Meanwhile, $7,1 \%$ believed it would be done in a hybrid or classical manner (see Figure 7).

Figure 7

Beliefs regarding the pedagogical process in the future

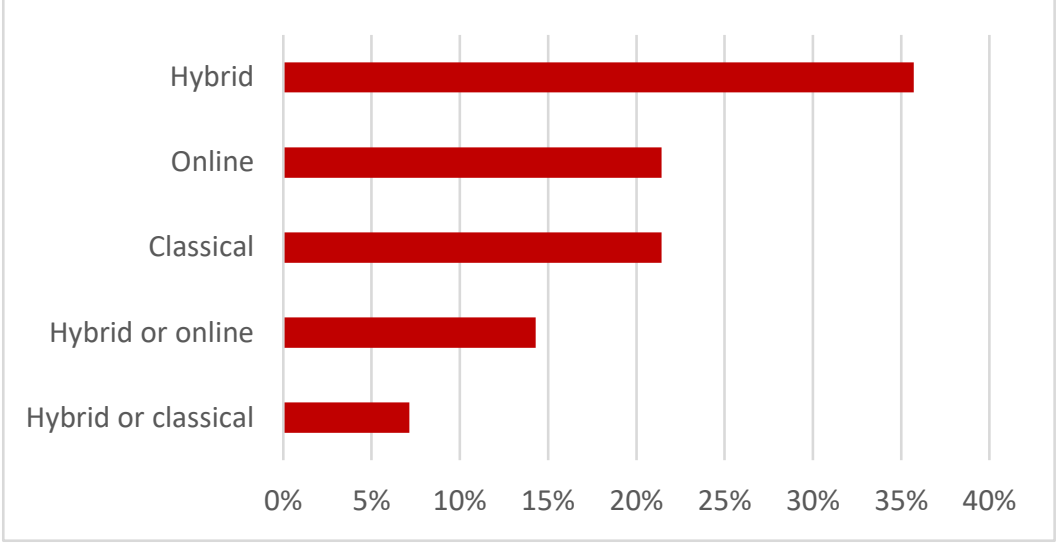

Source: Authors' work

Figure 8 presents the problems students encountered during the transition to the online manner of the pedagogical process. Some students $(21,4 \%)$ needed some time at first to adjust to using new applications (e.g., Zoom, LockDown Browser). Meanwhile, the same percentage report they didn't experience any problems. Some students $(14,3 \%)$ had problems regarding equipment (e.g. earphones) or other technical problems, e.g. Internet connection (14,3\%). Nevertheless, students (all $71,0 \%)$ also said that some professors were not familiar with IT, they missed the uniform way of publishing study material and announcements, no personal contact, ambient related problems - e.g., more people working from home, creating noise, health-related issues due to too much time spent on the computer (eyes problems) as well as relocation and adaptation to a new home due to closed students' dorms.

Figure 8

Problems students encountered during the transition to the online manner of the pedagogical process.

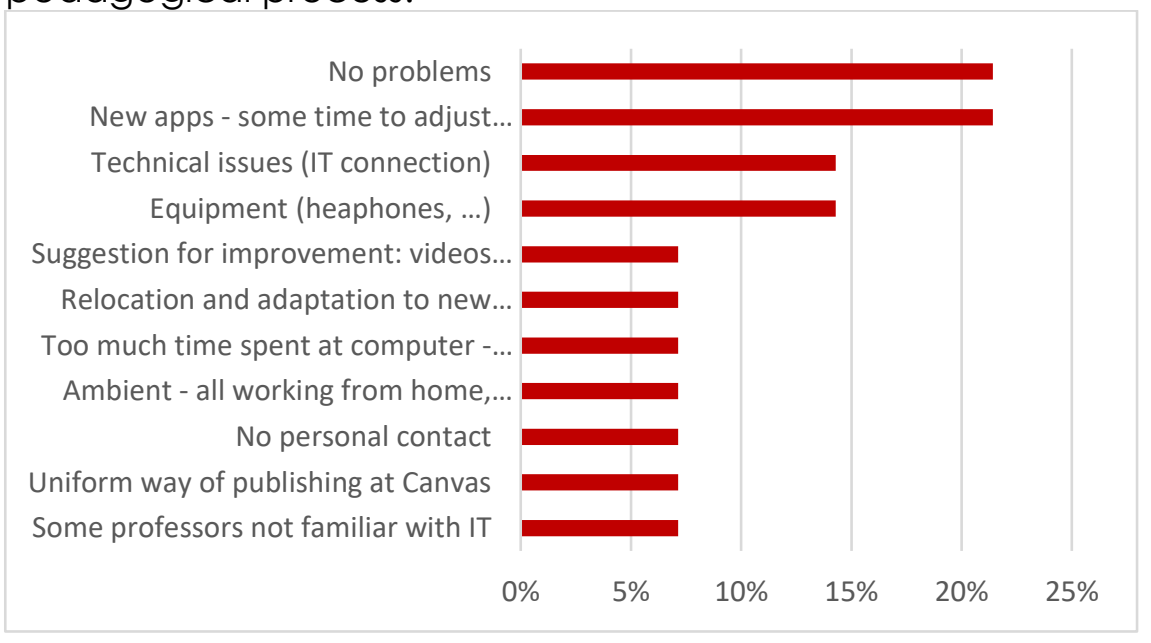

Source: Authors' work

We also asked the students about their preferred type of pedagogical work, as presented in Figure 9. 13 students replied. Not surprisingly, 30,8\% of students would 
prefer online courses (Kelly, 2021) in the future. The same percentage would prefer a combination, lectures are done online, while other work to be done in-person (practical seminars, exams). 15,4\% opted for the classic pedagogical process, with an additional $7,7 \%$ for classic, but with recorded lectures so they would have the option to listen to it again. $7,7 \%$ also preferred a combination of online and classic, with no specific details.

Figure 9

Preferred type of pedagogical work

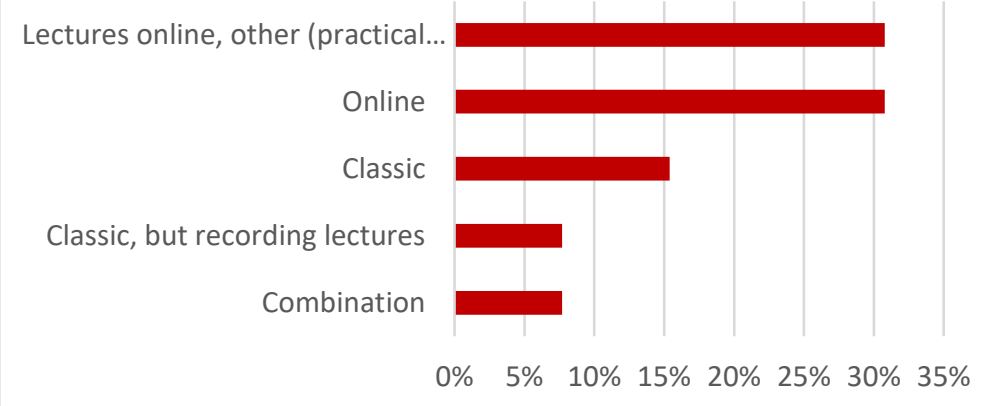

Source: Authors' work

Negative perceptions prevail despite the belief that it is easier to cheat during the online examination (Newton, 2020) among pedagogical staff (see Figure 10). Half of the respondents are afraid of possible technical issues, which might occur during the examination. $21,4 \%$ also complained about numerous rules they had to follow and were not the same for different courses and the technical requirements (e.g., apps), $21,4 \%$. $14,3 \%$ of respondents are afraid someone might interrupt them while examination (e.g., other family members walking in the room), and $14,2 \%$ find the online examination less stressful. One student also believed online exams were adopted and, therefore, more difficult content-wise.

Meanwhile, other positive experiences can be compared to classical examination regarding equal possibilities for all due to LockDown browsers or no need for commuting. Meanwhile, one student answered when an exam is done entirely online, it is a positive experience. Meanwhile, they had to write on paper and later scanned and upload it (e.g., when drawings are required) as primitive. At the Faculty, a vast majority are written exams.

Figure 10: Students' perceptions regarding online examination

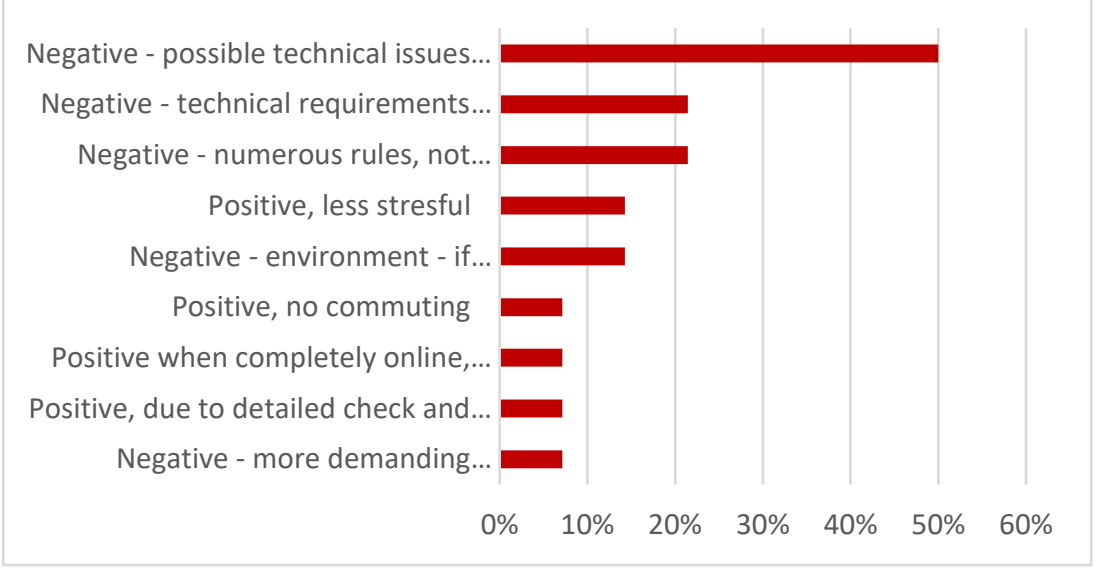

Source: Authors' work 
Most students believe that the course's content determines whether it is more appropriate to be done online or classically (75\%), while $16,7 \%$ didn't agree. One student out of $12(8,3 \%)$ who answered this question believed it is up to a professor and not the content.

\section{Discussion and Conclusion}

Our study contributes to the research on challenges of the COVID-19 pandemic on the transition to online learning in the higher education segment by elucidating the process of emergent transition which students encountered during the transition to online learning. Based on the content analysis, we have identified and conceptualized the changes related to COVID-19 as perceived by students, advantages of online study, and disadvantages of an online study employing Nvivo analysis.

The analysis shows that students' responses to the COVID-19 pandemic ranged from negative to neutral, mixed, and positive. We believe it depends on individual personality traits as well as the current situation of an individual. The fact is that at the age of 22 or 23 , life is very fluid, people search for their place, for stability in their lives, in terms of professional as well as private lives, especially in the fast-changing environment of the $21^{\text {st }}$ century, which is even more challenging during the pandemic. The rate of health-related challenges increased significantly during the pandemics (Lange, 2020), and students are no exception to the increase. Lack of socialization is experienced by the majority, as the pandemic decreases options to meet with other people in person, especially during the lockdowns. Social isolation, changes in daily routines and habits, maybe even loss of beloved ones may have significant consequences. Therefore, we believe exceptional instructors should also give special attention to vulnerable students who have experienced mental healthrelated challenges due to pandemics. Measures should be taken to be more susceptible to possible issues after enabling students to contact professional help (e.g., organized within the University).

The identified advantages of the transition to online study align with previous studies (Dhawan, 2020), ranging from increased time and space flexibility to improved time management and work-life balance. The vital facet is the cost savings in terms of no need for commuting and increased cosines. However, also this might be perceived negatively, as some students do not have an appropriate study environment at home (e.g., noise, other family members working from home, technical or monetary issues). However, it might also be perceived negatively in terms of a more extended working hour and inability to separate private and study/working life.

Nevertheless, despite established Zoom etiquette (see Figure 11) requiring students to turn on cameras, most prefer having their cameras off. Some also do other activities while participating in the pedagogical process (multitasking). Some students also experience less anxiety and tremor and are more willing to contribute to discussions, maybe when the camera is off or feel safer at home. Some students dedicate more time to studying and improving their work-life balance. Meanwhile, others found it more challenging due to multitasking and not being able to participate fully. 
Figure 11

Zoom Etiquette

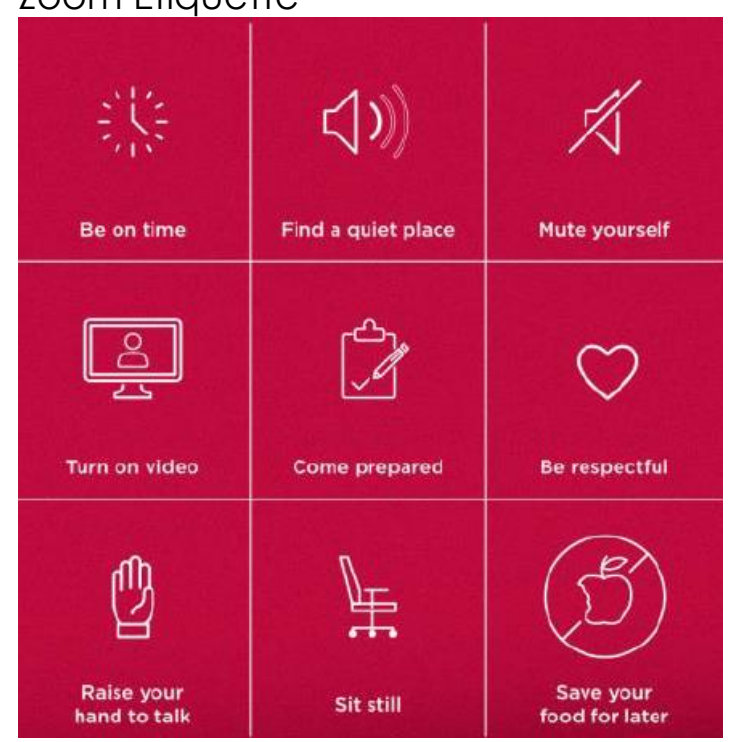

Source: School of Economics and Business, University of Ljubljana

The key disadvantage of online study is the lack of social contact with schoolmates. Therefore, we suggest structuring the pedagogical process to allow students to interact, maybe in smaller groups, allowing them extra time to discuss non-content-related matters and increase the level of social interaction, although virtual. Regarding the technical problems, we suggest establishing technical support also for students, as not all of them are necessarily advanced in ICT and innovative technologies (Roblek et al., 2018), which would be able to support students, e.g., by guiding them via phone or virtual conferences how to implement specific course technological requirements (e.g., special applications, programs, etc.). Our study also has specific implications on research on online study. The courses conducted online need to be carefully designed to stimulate students' multiple intelligences (Peterlin et al., 2021) and adequately prepare them for entering the aging workforce (Calvazara et al., 2020).

In addition, our study illuminates the transition to online study in higher education by which specific external challenges of COVID-19 factor shit consideration of an online teaching process from being just "online" to being a socially enhanced learning environment. The study, therefore, uncovers the dynamics of the emergency of the transition to online teaching in higher education, identifying challenges, advantages, and disadvantages due to COVID-19 pandemics.

Due to the fact, our study is performed on a small sample, and some meaning could be lost in the translation of responses to the English language before performing NVivo analysis, future research could be done on a larger sample. We also advise comparing students' responses in different countries, as the measures are taken, and the duration of emergency online learning varies among different countries. It would also be interesting to know how the transition was done in other countries, with various technological development levels, different health systems, age structure, and other factors that might affect the measures taken, its duration, and the transition itself. 


\section{References}

1. Abrioux, D. (2008), "Foreword", In Andreson, T., Elloumi, F. (Ed.), Theory and Practice of Online Learning, Athabasca University, Athabasca, Canada, pp. ix-xi.

2. Adnan, M., Anwar, K. (2020), "Online Learning amid the COVID-19 Pandemic: Students' Perspectives", Journal of Pedagogical Sociology and Psychology, Vo. 2 No. 1, pp. 45-51.

3. Ally, M. (2008), "Foundations of Educational Theory for Online Learning", Andreson, T., Elloumi, F., Theory and Practice of Online Learning, Athabasca University, Athabasca, Canada, pp. 3-31.

4. Baczek, M., Zagańczyk-Baczek, M., Szpringer, M., Jaroszyński, A., Wożakowska-Kapłon, B. (2021), "Students' perception of online learning during the COVID-19 pandemic: a survey study of Polish medical students", Medicine, Vol. 100 No. 7, e24821.

5. Calzavara, M., Battini, D., Bogataj, D., Sgarbossa, F., Zennaro, I. (2020), "Ageing workforce management in manufacturing systems: state of the art and future research agenda", International Journal of Production Research, Vol. 58 No. 3, pp. 729-747.

6. Covid-19 Sledilnik (2021), "Covid-19 Sledilnik", available at: https://covid19.sledilnik.org/en/stats (13 May 2021)

7. Dhawan, S. (2020), "Online learning: A panacea in the time of COVID-19 crisis", Journal of Educational Technology Systems, Vol. 49 No. 1, pp. 5-22.

8. European Commission (2021), "Safe vaccines COVID-19 for Europeans" (in Slovene), available at: https://ec.europa.eu/info/live-work-travel-eu/coronavirus-response/safecovid-19-vaccines-europeans_sl (13 May 2021)

9. Fauci, A. S., Lane, H. C., Redfield, R. R. (2020), "Covid-19 - navigating the uncharted", The New England journal of medicine, Vol. 382, pp. 1268-1269.

10. Fauzi, I., Khusuma, I. H. S. (2020), "Teachers' elementary school in online learning of COVID-19 pandemic conditions", Jurnal Iqra': Kajian IImu Pendidikan, Vol. 5 No. 1, pp. 58-70.

11. Government of the Republic of Slovenia (2020), „Review of all government measures to prevent the spread of the epidemic, March 16" (in Slovene), available at: https://www.iusinfo.si/medijsko-sredisce/dnevne-novice/259501 (12 May 2021)

12. Hodges, C., Moore, S., Lockee, B., Trust, T., Bond, A. (2020), "The difference between emergency remote teaching and online learning", Educause review, Vol. 27, pp. 1-12.

13. Kelly, R. (2021), "73 Percent of Students Prefer Some Courses Be Fully Online PostPandemic", available at: https://campustechnology.com/articles/2021/05/13/73percent-of-students-prefer-some-courses-be-fully-online-post-pandemic.aspx (10 June 2021)

14. Lange, K. W. (2020), "Mental health problems in COVID-19 and the need for reliable data", Movement and Nutrition in Health and Disease, Vol. 4, pp. 64-69.

15. Moore, J. L., Dickson-Deane, C., Galyen, K. (2011), "E-Learning, online learning, and distance learning environments: Are they the same?", The Internet and Higher Education, Vol. 14 No. 2, pp. 129-135.

16. Mukhtar, K., Javed, K., Arooj, M., Sethi, A. (2020), "Advantages, Limitations and Recommendations for online learning during COVID-19 pandemic era", Pakistan journal of medical sciences, Vol. 36 (COVID19-S4), S27-S31.

17. Newton, D. (2020), "Another problem with shifting education online: cheating", available at: https://hechingerreport.org/another-problem-with-shifting-educationonline-cheating/ (10 June 2021)

18. Peterlin, J., Dimovski, V., Meško, M., Roblek, V. (2021), "Cultivating Management Education Based on the Awareness of Students' Multiple Intelligences", SAGE Open, Vol. 11 No. 1, p. 1-12.

19. Roblek, V., Mesko, M., Dimovski, V., Peterlin, J. (2019), "Smart technologies as social innovation and complex social issues of the Z generation", Kybernetes, Vol. 48 No.1, pp. 91-107.

20. Stemler, S. (2000), "An overview of content analysis", Practical assessment, research, and evaluation, Vol. 7 No. 1, pp. 1-6. 
21. Tanis, C. J. (2020), "The seven principles of online learning: Feedback from faculty and alumni on its importance for teaching and learning", Research in Learning Technology, Vol. 28, pp. 1-25.

22. Velavan, T. P., Meyer, C. G. (2020), "The COVID-19 epidemic", Tropical medicine \& international health, Vol. 25 No. 3, pp. 278-280.

23. World Health Organization (2021), "WHO Coronavirus (COVID-19) Dashboard", available at: https://covid19.who.int/table (13 May 2021)

\section{About the authors}

Barbara Grah, Ph.D., is an Assistant Professor of management and organization at the School of Economics and Business, University of Ljubljana. Barbara teaches the Foundations of management and organization, Foundations of Management, Learning and Knowledge management, Strategic management 1, and Advanced management courses. Barbara obtained her Ph.D. in 2016, and her research interests are organization design, leadership, learning organization, and age management. The author can be contacted at barbara.grah@ef.uni-lj.si

Sandra Penger, Ph.D., is a Full Professor of management and organization at the Academic Unit for management and organization at the University of Ljubljana, School of Economics and Business in Slovenia, with more than 24 years of working experience in higher education, research, and consulting. She received her Ph.D. degree in 2006. Her research interests focus on leadership, authentic leadership, positive psychology in leadership, employee motivation, and advanced management concepts in the era of complexity (time management, selforganization, empowerment, personal energy management, workplace wellbeing). She has published over 100 original scientific papers/scientific conference contributions/scientific monographs/reviewed university books and participated in national and international projects. The author can be contacted at sandra.penger@ef.uni-lj.si 